\title{
What controls the occurrence of shallow intraplate earthquakes?
}

\author{
Yoshihisa Iio $^{1}$, Takeshi Sagiya ${ }^{2}$, and Yoji Kobayashi ${ }^{3}$ \\ ${ }^{1}$ Research Center for Earthquake Prediction, Disaster Prevention Research Institute, Kyoto University, Gokasho, Uji 611-0011, Japan \\ ${ }^{2}$ Research Center for Seismology, Volcanology and Disaster Mitigation, Nagoya University, Chikusa-ku, Nagoya 464-8602, Japan \\ ${ }^{3}$ Institute for Geoscience, University of Tsukuba, Tsukuba, Ibaragi 305-0006, Japan
}

(Received April 30, 2004; Revised October 10, 2004; Accepted December 15, 2004)

\begin{abstract}
We simulated the occurrence of both intraplate and interplate earthquakes in a simple spring-slider-dashpot model that includes both types of earthquake faults. We found that recurrence intervals of intraplate earthquakes are not controlled by the velocity of the relative plate motion but by the viscosity in the ductile fault zone, the coefficients of friction of both the interplate and intraplate earthquake faults, and the stress drop of intraplate earthquakes, when the stress drop of intraplate earthquakes is assumed to be only a small part of the total shear stress. These findings may open new avenues for the physics-based long-term forecasting of intraplate earthquakes.
\end{abstract}

Key words: Intraplate earthquake, lower crust, recurrence interval, ductile fault zone.

\section{Introduction}

Shallow intraplate earthquakes cause enormous damage, however, the mechanisms by which intraplate earthquakes occur has been poorly understood and is still controversial (e.g., Campbell, 1978; Hinze et al., 1988; Iio and Kobayashi, 2002; Liu and Zoback, 1997; Sykes, 1978), in contrast to interplate earthquakes, for which mechanisms are clearly explained by the plate tectonics theory.

The following basic problems have not been resolved. 1) Why and how is the stress accumulated on intraplate earthquake faults, despite the fact that stress at nearby plate boundaries is released quasi-periodically and is apparently not accumulated over the recurrence interval of interplate earthquakes? 2) Why do intraplate earthquakes occur far from the plate boundary region, even though strain rates decrease with distance from the plate boundary?

Past studies often attribute the origin of intraplate earthquakes to heterogeneity in the crust, in particular in the lower crust (e.g., Kenner and Segall, 2000; Stuart et al., 1997). Although these models can explain the above question 2), about the location of intraplate earthquakes, they cannot generate periodic intraplate earthquakes over a long time period, since the interaction between interplate and intraplate earthquakes are not included and boundary conditions are not adequately assumed in these model.

This study successfully demonstrates the occurrence of both intraplate and interplate earthquakes and explains variations in the recurrence interval of intraplate earthquakes, by using a simple model with spring, slider and dashpot elements.

Copy right(c) The Society of Geomagnetism and Earth, Planetary and Space Sciences (SGEPSS); The Seismological Society of Japan; The Volcanological Society of Japan; The Geodetic Society of Japan; The Japanese Society for Planetary Sciences; TERRAPUB

\section{Model Description}

Our conceptual model is shown in Fig. 1(a). The inland plate consists of the upper and lower crusts; Stress relaxation occurs in the uppermost mantle over a period longer than the recurrence interval of an intraplate earthquake (e.g., Matsu'ura and Sato, 1997) except for the portion adjacent to the interplate earthquake fault. This assumption is supported by several recently published studies that revealed the viscosity of the uppermost mantle in the intraplate region is much smaller than that of the lower crust (e.g., Kaufmann and Amelung, 2000; Nishimura and Thatcher, 2003; Ueda et al., 2003).

The intraplate earthquake fault is limited to the upper crust, while the interplate earthquake fault is in contact with the whole crust and also the rigid portion of the upper mantle. Thus, the intraplate earthquake fault sustains forces acting only in the upper crust, while the interplate earthquake fault sustains forces in both the upper and lower crusts. The downward extension of the intraplate earthquake fault is assumed to be a ductile fault zone with a low viscosity (e.g., Iio and Kobayashi, 2003; Sibson, 1983). The lower crust without a fault zone is assumed to have a large viscosity. The left-hand side end of the model is assumed to be a fixed displacement boundary. It is also assumed that the upper crust is elastic and that the viscosity of the upper mantle is very small and the interaction between the intraplate crust and the upper mantle can be disregarded. Then, this conceptual model predicts that the magnitude of the long-term average force acting in the intraplate crust does not decrease with distance from the plate boundary, as long as the fixed boundary condition is assumed. Intraplate earthquakes can be generated far from the plate boundary. Actually, in the central and eastern United States, various stress measurements show a pervasive generalized principal stress direction (Zoback and Zoback, 1980) and suggest that their origin is associated with the relative plate motion. Large in- 


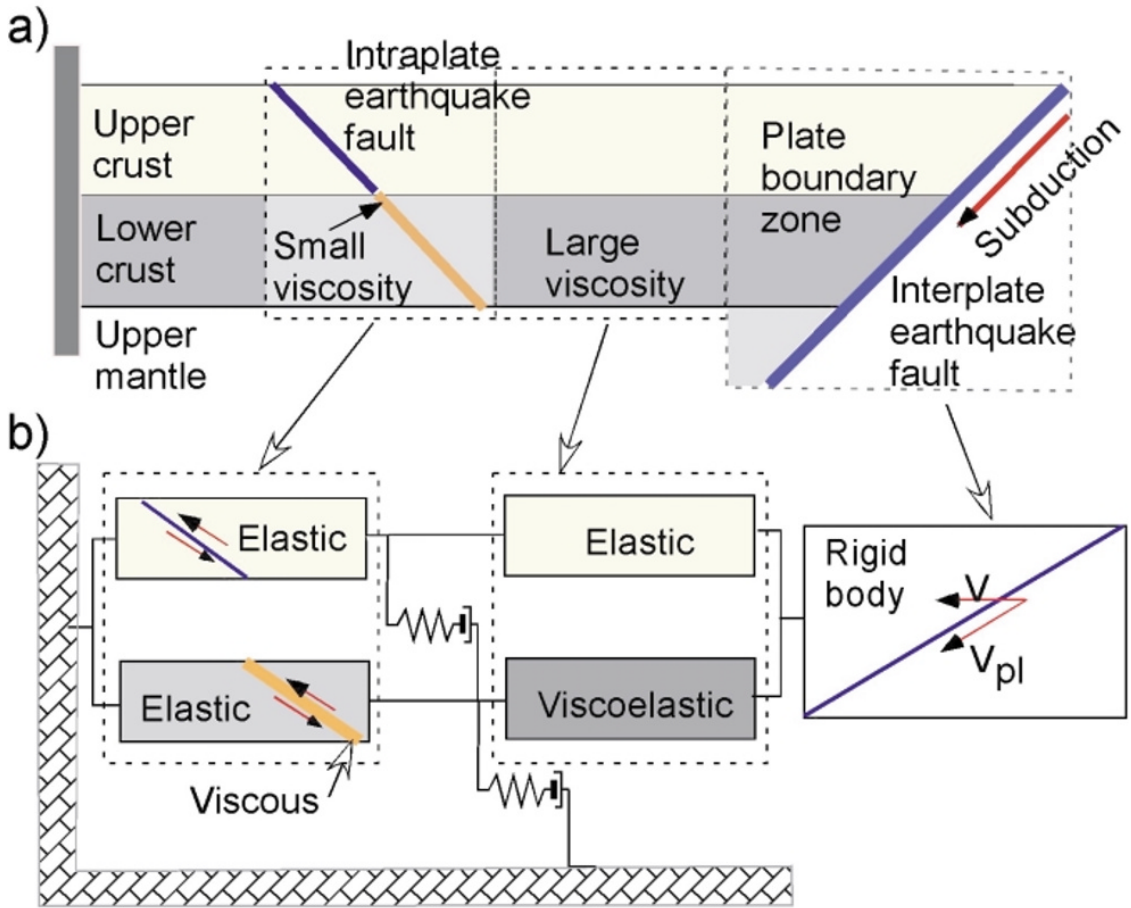

c)

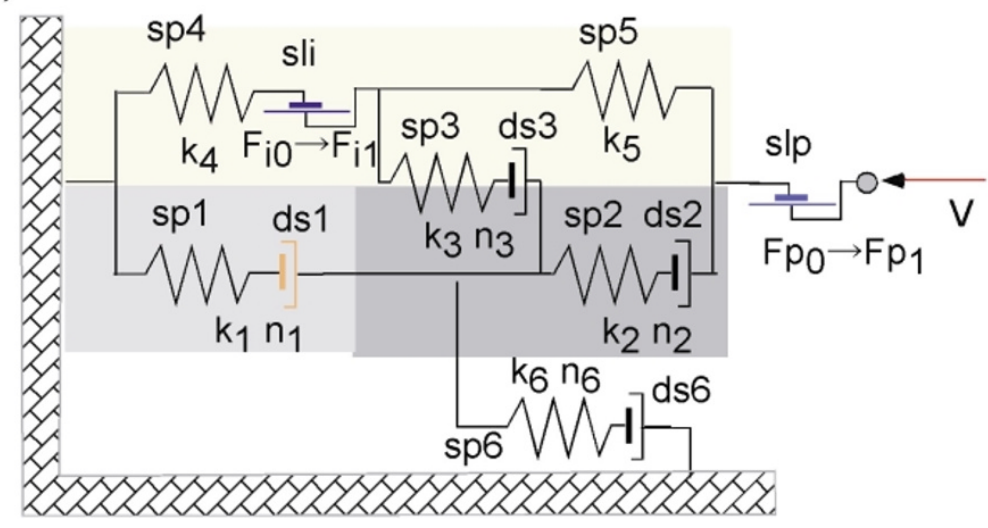

Fig. 1. An outline of the model. a) The conceptual model. The interplate earthquake fault is in contact with the upper and lower crust, and the portion of the upper mantle in the plate boundary zone. Stress relaxation occurs in the upper mantle, except for the portion adjacent to the interplate earthquake fault. The intraplate earthquake fault has a downward extension in the lower crust, which deforms in a ductile manner. The intraplate crust is divided into four portions as shown in b) and each portion is simply represented by elements as shown in c). $s p 1-s p 6$ represent springs with apparent spring constants, $k_{1}-k_{6} . d s 1-d s 6$ are dashpots with apparent viscosities of $n_{1}-n_{6}$. sli and $s l p$ are the sliders that represent the intraplate and interplate earthquake faults, respectively. Another spring and dashpot is introduced between the upper and lower crusts to couple them to each other. The lowermost spring and dashpot is designed to represent the uppermost mantle, but can be mostly disregarded in this study. Details are described in the text.

traplate earthquakes occurred in the New-Madrid seismic zone, which is one of the most remarkable intraplate seismic zones (Hinze et al., 1988).

It might be thought that the assumption of the fixed boundary condition is not appropriate. Past studies have assumed that the deformation resulting from the relative plate motion should be described by the dislocation in a semi-infinite medium (e.g., Matsu'ura and Sato, 1989; Hashimoto and Matsu'ura, 2004). However, the model of Hashimoto and Matsu'ura (2004) predicts that a certain level of absolute shear stress is maintained in the intraplate crust by the friction on plate boundary faults, thus, the assumption of the fixed boundary condition may be regarded as an approximation of this situation.
We constructed a simple model with spring, slider and dashpot elements to represent the above conceptual model. We first divided the intraplate crust into four portions, the upper crust with and without the intraplate earthquake fault, and the lower crust with and without the ductile fault zone, as shown in Fig. 1(b). The plate boundary zone acts as a stress guide between the interplate earthquake fault and the intraplate crust, when the upper mantle, except for the plate boundary zone, is relaxed. For simplicity, we assumed that the stress guide is a rigid body and that the lower crust surrounding the ductile fault zone is elastic. Each portion is represented by elements as shown in Fig. 1(c). Portions of the lower crust are constituted by spring and dashpot elements, while those of the upper crust by a spring el- 

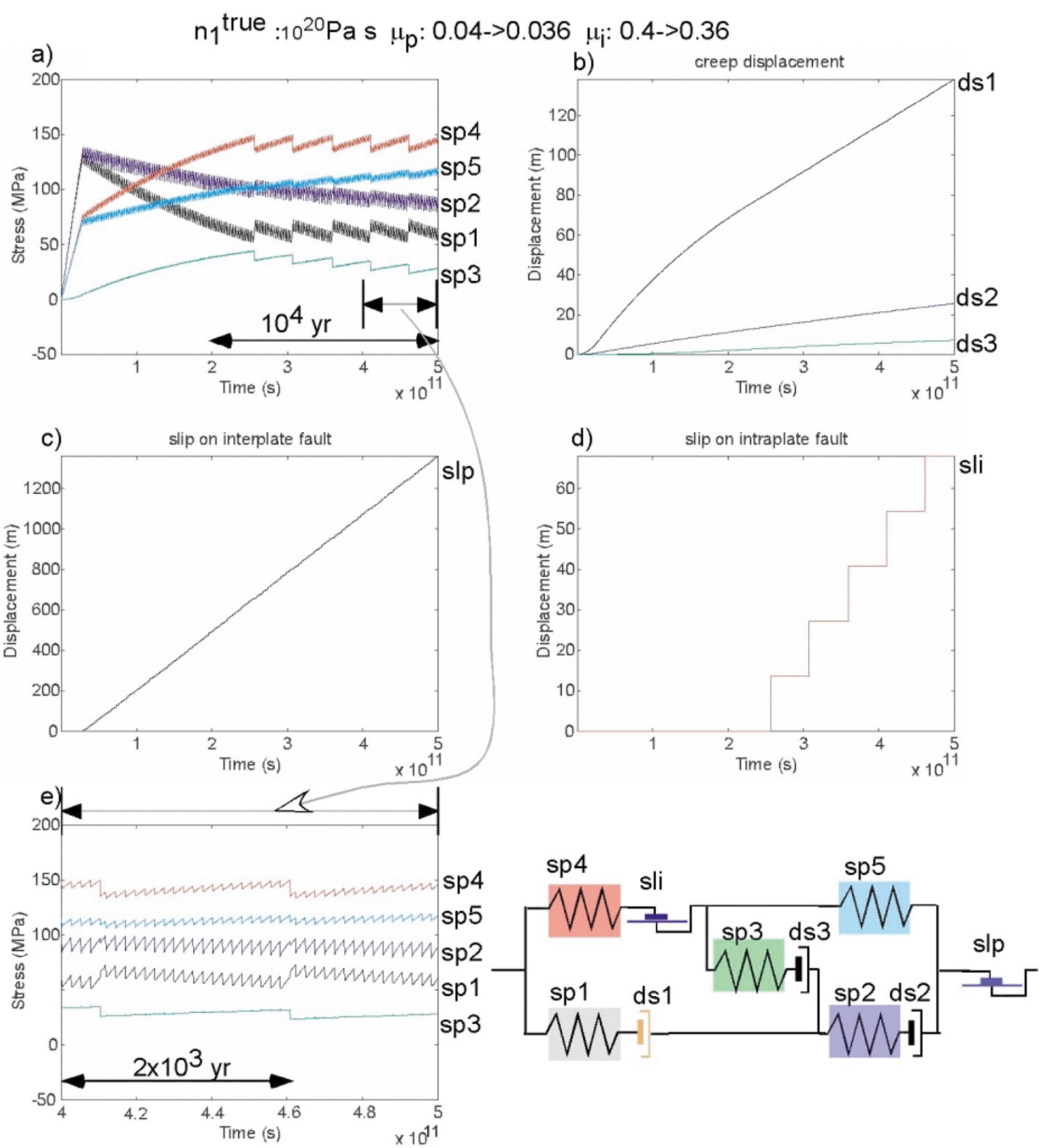

Fig. 2. A typical example of results obtained. a) Changes in stress magnitudes for the springs, $s p 1-s p 5$. The lines of $s p 4$ and $s p 1$ represent the stresses on the intraplate earthquake fault and its downward extension, respectively. Large stress drops are generated by intraplate earthquakes, and smaller ones by interplate earthquakes. The portion indicated by the open arrow is enlarged in e). b) Displacement of dashpots. The line of $d s 1$ shows the displacement of the ductile fault zone. c) Cumulative displacement on the interplate earthquake fault. At this scale, it is difficult to distinguish each event because of its short recurrence time. d) Cumulative displacement on the intraplate earthquake fault.

ement (and a slider element for the intraplate earthquake fault). The right-hand side slider, $s l p$, represents the interplate earthquake fault and is connected to both parts of the intraplate crust. The sliders ( $s l i$ and $s l p$ ) begin to slip when the stress acting on them becomes larger than their values of static friction, then the friction level suddenly decreases to a constant dynamic friction level. Another spring and dashpot is introduced between the upper and lower crusts to couple them to each other. The lowermost spring and dashpot is designed to represent the uppermost mantle, but can be mostly disregarded in this study (it is assumed to have a much smaller viscosity than the lower crust).
The right-hand side of the slider is pushed by the horizontal component of the relative plate motion velocity. Deformation of these elements is determined by equations of force balance and displacement continuity, and a constitutive relationship of the ductile fault zone (see Appendix). The system is quasi-static, namely mass is disregarded.

\section{Results}

The response of the system was investigated for different values of static and dynamic coefficients of friction of the intraplate and interplate earthquake faults, and viscosities in the ductile fault zone. 
Table 1. Fixed Parameter values. These values are fixed in this study. See details in the text. $L_{1}$ and $L_{2}$ are the length of the portion of the crust that includes and does not include the earthquake fault, respectively.

\begin{tabular}{lll}
\hline Parameter & Values & Explanations \\
\hline$V_{p l}$ & $10 \mathrm{~cm} / \mathrm{yr}$ & relative plate velocity \\
$D_{p}$ & $60 \mathrm{~km}$ & $\begin{array}{l}\text { coupling depth at the plate boundary } \\
\text { thickness of the upper crust }\end{array}$ \\
$D_{u}$ & $15 \mathrm{~km}$ & $\begin{array}{l}\text { thickness of the lower crust } \\
D_{l}\end{array}$ \\
Dip $p$ & $15 \mathrm{~km}$ & dip angle of the interplate earthquake fault \\
Dip $p_{i}$ & 30 & dip angle of the intraplate earthquake fault \\
$f_{w}$ & $1 \mathrm{~km}$ & width of the ductile fault zone \\
$L_{1}$ & $50 \mathrm{~km}$ & see above \\
$L_{2}$ & $50 \mathrm{~km}$ & see above \\
$E$ & $9.0 * 10^{10} \mathrm{~Pa}$ & Young's modulus in the upper crust \\
$E_{l}$ & $1.8 * 10^{11} \mathrm{~Pa}$ & Young's modulus in the lower crust \\
\hline
\end{tabular}

Table 2. Variable parameter values. These values are used in the simulations. $\mu_{p 0}$ and $\mu_{i 0}$ are the initial coefficients of friction for interplate and intraplate earthquake faults, respectively. $n_{1}^{\text {true }}$ is the true viscosity in the ductile fault zone. See details in the Appendix.

\begin{tabular}{ll}
\hline$\mu_{p 0}$ & $0.01,0.02,0.04,0.06,0.08,0.1,0.2,0.4$ \\
$\mu_{i 0}$ & $0.05,0.1,0.2,0.3,0.4,0.5,0.6,0.7,0.8,0.9,1.0$ \\
$n_{1}^{\text {true }}$ & $10^{19}, 10^{20}, 10^{21}, 10^{22} \mathrm{~Pa} \mathrm{~s}$ \\
\hline
\end{tabular}

Figure 2 shows a typical example of the results obtained. Parameter values that are fixed in this study are listed in Table 1. The width of the ductile fault zone is assumed to be $1 \mathrm{~km}$. The other parameters are changed as shown in Table 2 , and for this example, values of $\mu_{p 0}, \mu_{i 0}$, and $n_{1}^{\text {true }}$ are set as $0.04,0.4$, and $10^{20} \mathrm{~Pa} \mathrm{~s}$, respectively. A value of $n_{2}^{\text {true }}$ is set as one thousand times greater than that of $n_{1}^{\text {true }}$. The differences between static and dynamic coefficients of friction are set as 0.004 , and 0.04 for the interplate and intraplate earthquake faults, respectively. These parameter values are changed in the following simulations to investigate the relationship between the recurrence interval of intraplate earthquakes and these parameters. Here, values of $k_{1}-k_{3}$ are assumed to be twice of those of $k_{4}-k_{5}$, to adequately represent the strain field when either portion of the lower crust is completely relaxed.

At the beginning of the simulation, the crust is shortened by the relative plate motion. When the stress on the interplate earthquake fault reaches the level of static friction, an interplate earthquake occurs. After that, the stress in the crust, averaged over the vertical direction, is kept at an almost constant level, although it changes within a small extent with the friction on the interplate earthquake fault. Then, the ductile fault zone begins to relax and the stress sustained there is transferred to the upper crust.

When the stress on the intraplate earthquake fault reaches that due to the static friction, an intraplate earthquake occurs and a stress concentration is generated on the downward extension, namely the ductile fault zone. Then, stress relaxation begins in the ductile fault zone and stress is transferred to the upper crust. This system response is similar to that of a Foigt body.
The total force acting in the intraplate crust is decreased by the earthquake slip. Then, the crust is shortened to compensate for this decrease of the total force, and the stress in the crust is accumulated by the relative plate motion until the next interplate earthquake occurs. This stress build-up process is thought to be in accordance with the concept of the partial collision proposed by Hashimoto and Matsu'ura (2004), since a part of the relative plate motion velocity is consumed in internal deformation within the intraplate crust. This stress build-up process is not apparent in Fig. 2, since the stress drop of the intraplate earthquake is assumed to be only a small part of the total shear stress.

The above process is repeated over several cycles.

The lower crust without the fault zone has not yet been completely relaxed in the period shown in Fig. 2, however, the behavior of the ductile fault zone is the same after the portion of the lower crust was completely relaxed. In the following, we will mainly show results in this period, since the results in the beginning portions of the simulation are useful for understanding what is happening.

The recurrence interval of the intraplate earthquakes is determined by the stress drop and the deformation rate of the ductile fault zone, when the stress drop of the intraplate earthquake is assumed to be only a small part of the total stress. The deformation rate increases with increasing stress magnitude and decreasing viscosity in the fault zone. The stress in the fault zone increases with increasing friction on the interplate earthquake fault, and decreasing friction on the intraplate earthquake fault, since the total force acting in the crust is proportioned more to the lower crust than to the upper crust, when the friction of intraplate earthquake faults is small.

The dependence of the recurrence interval of intraplate earthquakes on the friction of the intraplate fault is demonstrated in Fig. 3(a). Compared to Fig. 2(a), it is found that a smaller $\mu_{i 0}$ produces a shorter recurrence interval of intraplate earthquakes. In the case of $\mu_{i 0}$ greater than 0.4 , however, intraplate earthquakes do not occur, even after the lower crust is completely relaxed, since the static frictional strength of the intraplate earthquake fault is greater than the stress that can be generated by the relative plate motion under the assumed $\mu_{p 0}$. 
a) $n_{1}$ true $: 10^{20} \mathrm{~Pa} \mathrm{~s} \mu_{\mathrm{p}}: 0.04->0.036$

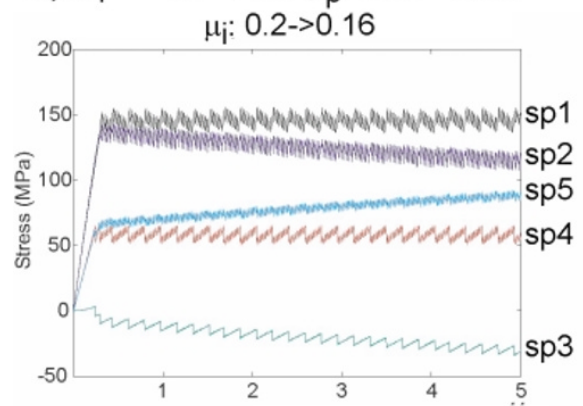

b) $n_{1}$ true $: 10^{20} \mathrm{~Pa} \mathrm{~s} \mu_{\mathrm{j}}: 0.4->0.36$

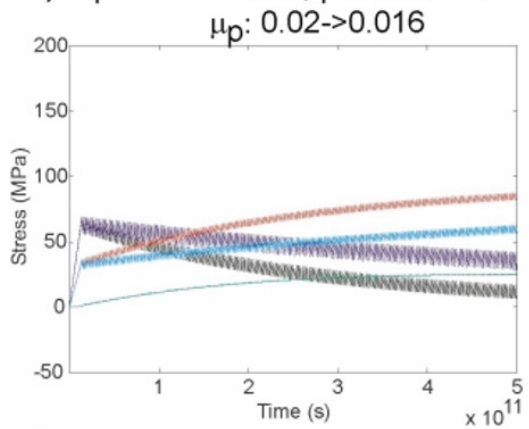

c) $\mu_{\mathrm{p}}: 0.04->0.036 \mu_{\mathrm{i}}: 0.4->0.36$

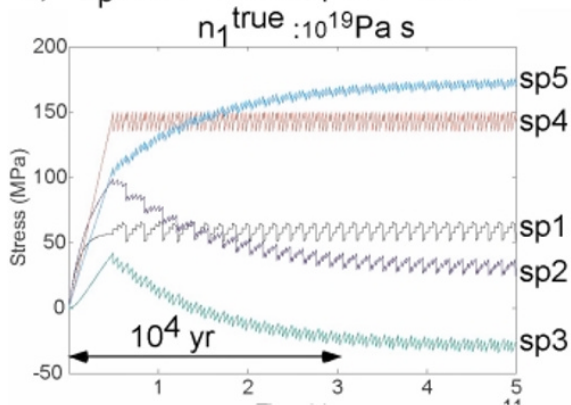

d) $\mathrm{n}_{1}$ true $: 10^{20} \mathrm{~Pa} \mathrm{~s} \mu_{\mathrm{p}}: 0.04->0.036$

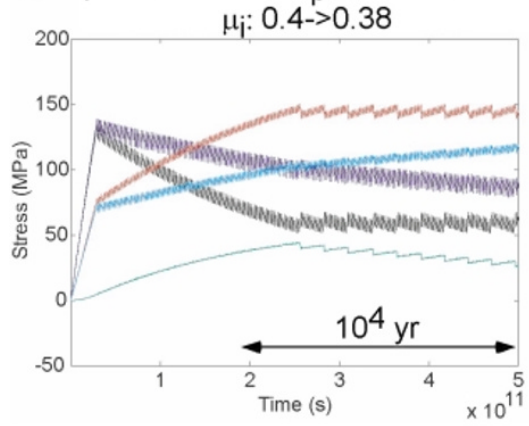

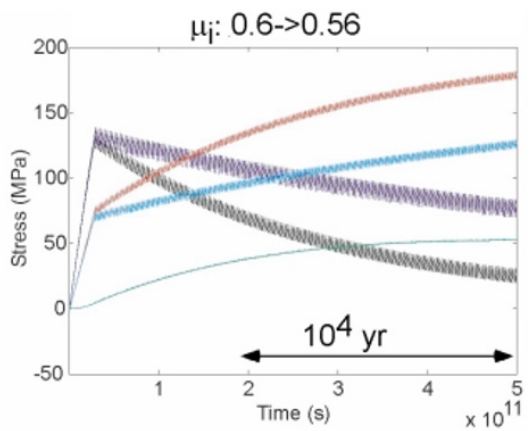
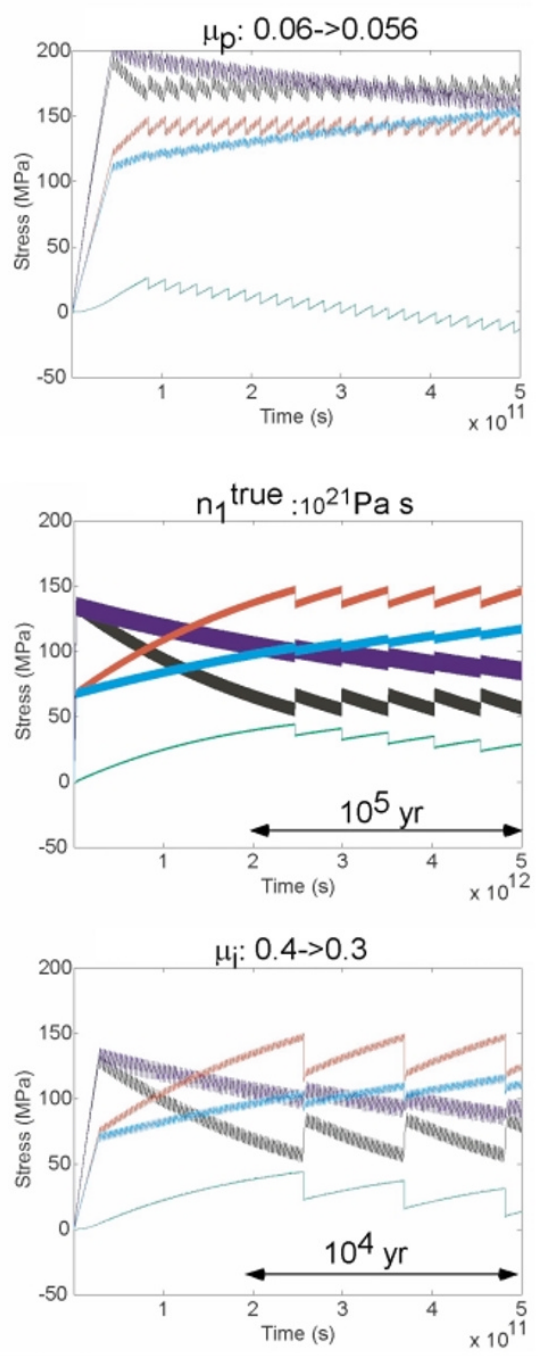

Fig. 3. Results demonstrating the dependences of the recurrence interval of intraplate earthquakes for various parameters. a) Friction of the intraplate fault. b) Friction of the interplate earthquake fault. c) Viscosity in the ductile fault zone. d) Stress drop of intraplate earthquakes. Changes in stress magnitudes for the springs, $s p 1-s p 5$ are displayed. Vertical scales are the same in all the figures, while horizontal are different.

The dependence of the recurrence interval of intraplate earthquakes on the friction of the interplate earthquake fault is demonstrated in Fig. 3(b). It is found that larger $\mu_{p 0}$ produces shorter recurrence intervals of intraplate earthquakes, however, for smaller values of $\mu_{p 0}$, such as 0.2 , intraplate earthquakes do not occur.

Figure 3(c) demonstrates the dependence of the recurrence interval on the viscosity in the ductile fault zone. A higher viscosity produces longer recurrence intervals of intraplate earthquakes. It was found from the simulations us- ing viscosities greater than $10^{20} \mathrm{~Pa}$ s that the recurrence interval is basically proportional to the viscosity. Actually, the right-hand side panel is very similar to that in Fig. 2(a) except that the time axis is longer by an order of magnitude. On the other hand, the behavior of the system is different for much smaller viscosities. In the case of $10^{19} \mathrm{~Pa} \mathrm{~s}$, shown in the left-hand side panel, the ductile fault zone is already relaxed before interplate earthquakes begin to occur. In this case, intraplate earthquakes occur first, and before the increased stress in the ductile fault zone returns to the level 

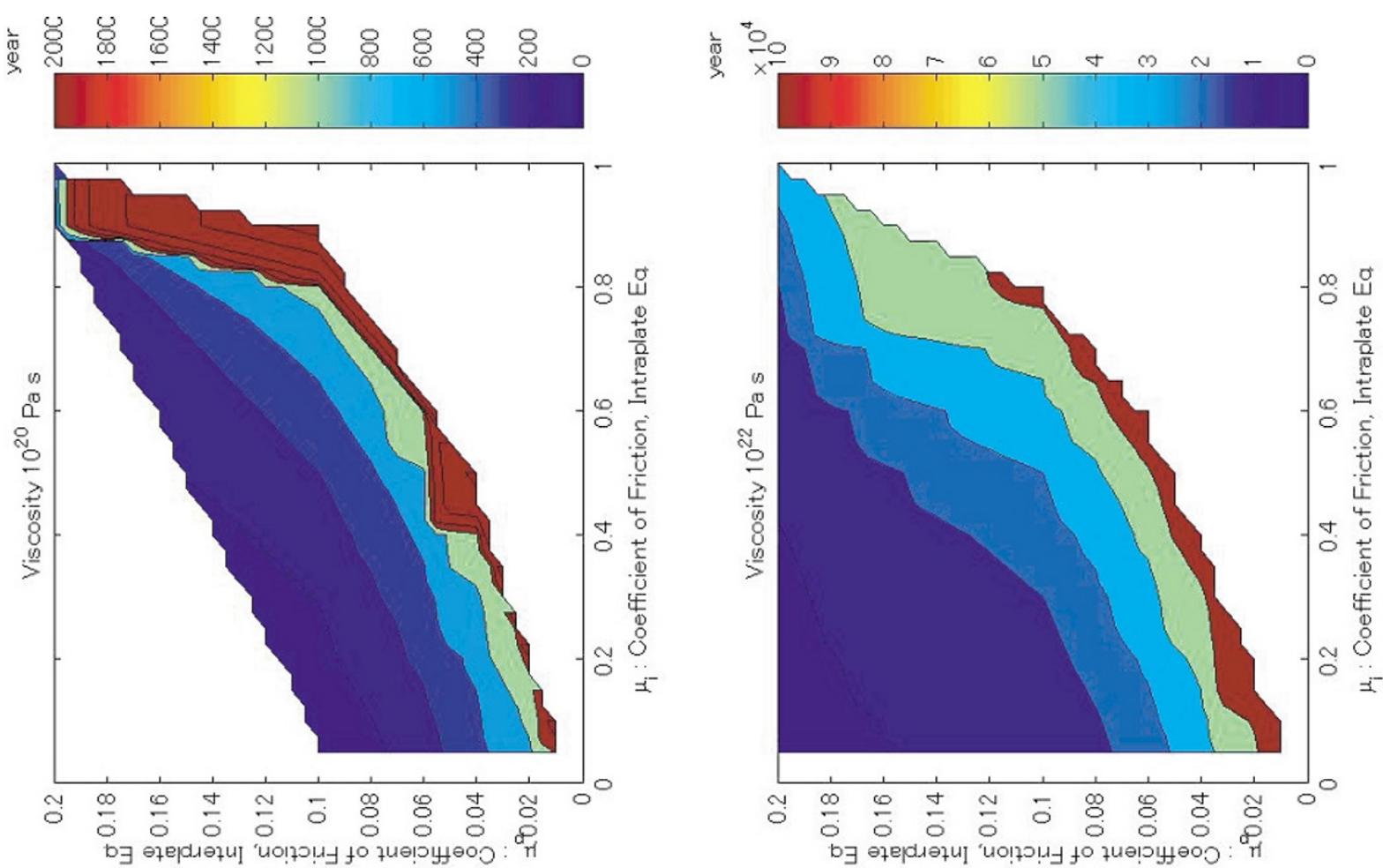

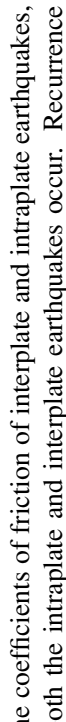

范

弯

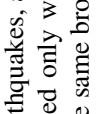
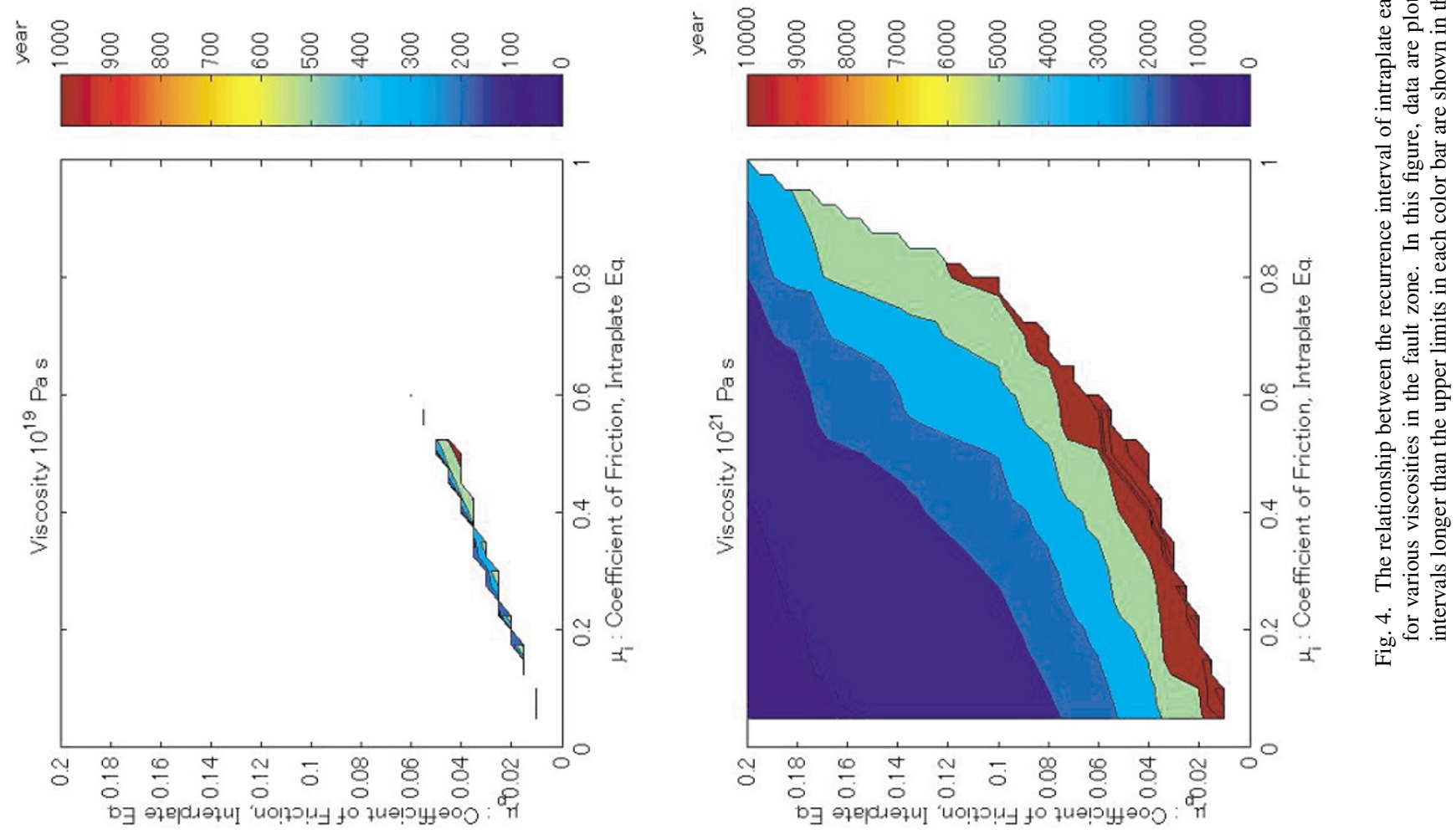


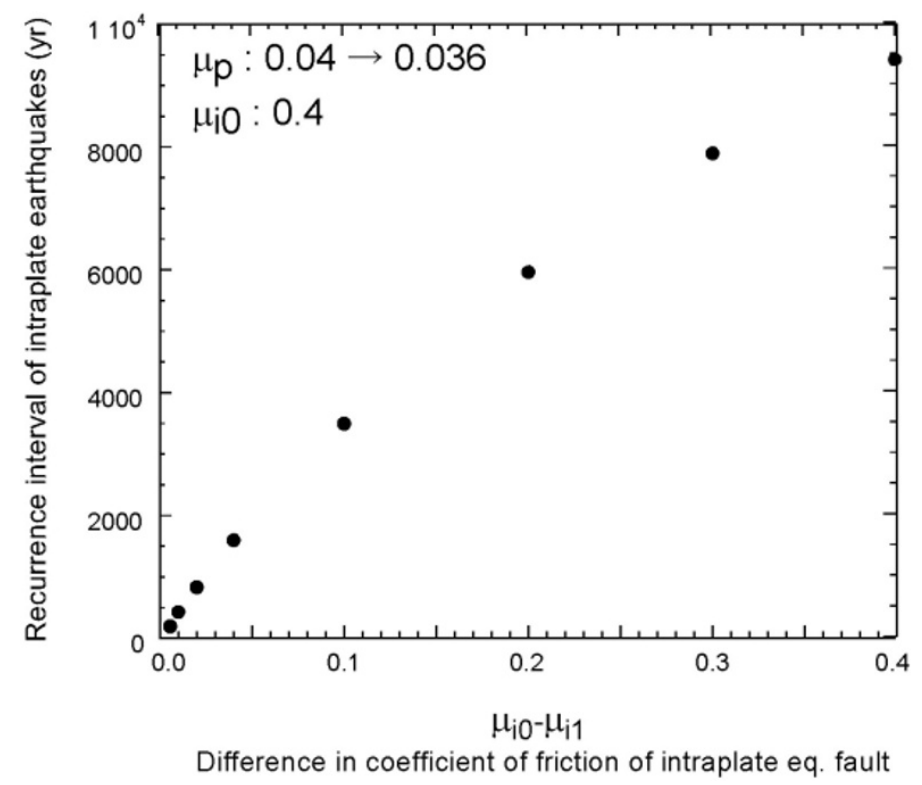

Fig. 5. The relationship between the recurrence interval of intraplate earthquakes and their stress drops. The parameter on the horizontal axis is the difference between the initial and final coefficients of friction.

immediately before the intraplate earthquake, the next intraplate earthquake occurs. Then, the stress is accumulated on the interplate earthquake fault. In this case, the recurrence interval of intraplate earthquakes is shorter than that of interplate earthquakes.

The dependence of the recurrence interval on the stress drop of intraplate earthquakes is demonstrated in Fig. 3(d). Larger stress drops produce longer recurrence intervals of intraplate earthquakes.

We repeated almost the same simulations using a relative plate velocity that was half of the velocity used in the first simulations. We found that the velocity does not affect the recurrence interval of intraplate earthquakes, but only affects the recurrence interval of the interplate earthquakes. This result implies that intraplate earthquakes are not controlled by the velocity of the relative plate motion but by the stress level at the plate boundary, when the stress drop of the intraplate earthquake is assumed to be only a small part of the total stress.

Figure 4 summarizes the relationship between the recurrence interval of intraplate earthquakes, and the coefficients of friction of the interplate and intraplate earthquakes for different viscosities in the fault zone. Simulations were done using the parameter values listed in Table 2 and the interpolated results are shown. It is found that the recurrence interval is almost proportional to the viscosity in the fault zone for larger viscosities. No data are plotted for larger coefficients of friction for the intraplate faults and smaller coefficients of friction for the interplate faults, since the stress accumulated on the intraplate earthquake fault does not reach these high static friction levels. Also, for smaller viscosities, no data are also plotted for smaller coefficients of friction for intraplate faults and larger coefficients of friction for interplate faults, since interplate earthquakes do not occur. The reason why interplate earthquakes do not occur is that the ductile fault zone has already relaxed due to the small viscosity and then the stress on the interplate earth- quake fault is not accumulated after the intraplate earthquakes begin to occur. Furthermore, for smaller viscosities, recurrence intervals longer than a few thousands of years are accomplished only for very limited combinations of coefficients of friction.

The relationship between the recurrence intervals of intraplate earthquakes and the stress drops of intraplate earthquakes is shown in Fig. 5. It is found that the recurrence interval increases with stress drop. The reason the dependence is not linear is that stress in the ductile fault zone averaged over the recurrence interval for larger stress drops, is larger than for smaller ones.

\section{Discussion and Concluding Remarks}

We will compare these results with observational data. In the Japanese Islands, recurrence intervals of intraplate earthquakes vary from several hundred years to a few tens of thousands of years, and usually they are longer than a thousand years (e.g., Research Group for Active Faults of Japan, 1980). On the other hand, the stress drops of large intraplate earthquakes only vary at most by one order of magnitude (e.g., Kanamori and Anderson, 1975). Consequently, it is difficult to explain this large variation in the recurrence intervals by the difference in stress drop. It is likely that it is attributed to the viscosity in the ductile fault zone, and/or the coefficients of friction of the interplate and intraplate earthquake faults.

It is seen in Fig. 4 that a range in viscosity in the fault zone of $10^{20}$ to $10^{21} \mathrm{~Pa}$ s can explain the variation of the recurrence intervals. In this study, we assumed the width of the ductile fault zone to be $1 \mathrm{~km}$. The viscosities estimated here increase with the assumed width of the ductile fault zone. However, the upper limit is estimated to be about $10^{23} \mathrm{~Pa} \mathrm{~s}$, since it is not reasonable to assume widths greater than a few tens of kilometers. In this case, deformation is not localized but distributed in the lower crust.

In some cases for smaller viscosities, it is found that the 
recurrence interval of intraplate earthquakes is shorter than that of interplate earthquakes, as shown in the left-hand side panel in Fig. 3(c). The cumulative displacement of intraplate earthquake faults is larger than that of interplate earthquake faults, since the amount of earthquake slip is of the same order for the intraplate and interplate earthquakes. For this type of result, it may be necessary to re-examine the definition of the plate boundary.

There is a trade-off between the coefficients of friction of the intraplate and interplate earthquake faults, and we only determined possible pairs of their values for a certain recurrence interval of intraplate earthquakes, as shown in Fig. 4. In this study, it is estimated that the coefficient of friction of the interplate earthquake fault is much smaller than for the intraplate earthquake fault. This is because the coupling depth of the interplate earthquake fault is assumed to be larger than the width of the upper crust, where the intraplate earthquake fault exists. Furthermore, although we attributed the small friction at the plate boundary to the small coefficient of friction, assuming hydrostatic pore pressure, very high pore pressures can also explain the small friction.

If the stress drop of the intraplate earthquake is assumed to occupy a larger part of the total shear stress, it takes a longer time to build up the stress in the intraplate crust to the level at which interplate earthquakes occur. The delay time is controlled by the stress drop, the relative plate motion velocity, and the viscosity in the ductile fault zone. Thus, in this case, the recurrence interval of intraplate earthquakes is also affected by the relative plate motion velocity.

The model presented in this paper is two-dimensional and simplified compared to the real intraplate crust and plate boundary. For a three-dimensional model, in which there are the edges of the intraplate earthquake fault in the upper crust, the stress concentration in the ductile fault zone from the occurrence of intraplate earthquakes is thought to be smaller than that predicted in this paper, since stress concentrations occur not only in the lower crust just beneath the earthquake fault, but also in the surrounding upper crust. However, the role of the ductile fault zone in the lower crust is thought to be essential, since the viscosity in the upper crust is expected to be much larger than the values for the ductile fault zone estimated in this paper and stress relaxation does not occur in the surrounding upper crust in the period equivalent to the recurrence intervals of intraplate earthquakes (e.g., Kaufmann and Amelung, 2000; Nishimura and Thatcher, 2003; Ueda et al., 2003).

Acknowledgments. The authors thank James Mori who critically reviewed the manuscript. The authors are grateful for Mitsuhiro Matsu'ura and Susan Ellis for their thoughtful reviews and valuable suggestions. This study is partly supported by a grant from the Comprehensive Joint Research of the Special Coordination Funds for Promoting Science and Technology, 'the Comprehensive Research on Slip and Flow Processes in and below the Seismogenic Region'.

\section{Appendix A.}

Detailed calculations are done as follows. The right-hand side of the slider, slp, shown in Fig. 1(c) is pushed by the velocity, $V$, corresponding to the horizontal component of the relative plate motion velocity. We assume that at a time $t=0$, the system is under a static equilibrium stress state, namely the lithostatic stress state (e.g., McGarr, 1988). Displacement of the $i$-th spring ( $s p i), U_{s p i}$ at a time, $t$ relative to this reference state is calculated under the velocity boundary condition as,

$$
\begin{gathered}
{\left[\begin{array}{cccccc}
1 & 1 & 0 & 0 & 0 & 0 \\
0 & 0 & 0 & 1 & 1 & 0 \\
0 & 1 & 1 & 1 & 0 & 0 \\
k_{1} & -k_{2} & k_{3} & 0 & 0 & -k_{6} \\
0 & 0 & k_{3} & -k_{4} & k_{5} & 0 \\
1 & 0 & 0 & 0 & 0 & 1
\end{array}\right]\left[\begin{array}{c}
U_{s p 1} \\
U_{s p 2} \\
U_{s p 3} \\
U_{s p 4} \\
U_{s p 5} \\
U_{s p 6}
\end{array}\right]} \\
=\left[\begin{array}{c}
V t-U_{d s 1}-U_{d s 2}-U_{s l p} \\
V t-U_{s l p}-U_{s l i} \\
V t-U_{d s 2}-U_{d s 3}-U_{s l p}-U_{s l i} \\
0 \\
0
\end{array}\right], \\
-U_{d s 1}-U_{d s 6}
\end{gathered}
$$

where $U_{d s i}$ is the displacement of the $i$-th dashpot ( $\left.d s i\right)$, $U_{s l p}$ and $U_{s l i}$ are displacements of the sliders slp and sli, respectively. These values are equal to zero at $t=0 . k_{1}$ to $k_{6}$ are the apparent spring constants. The meaning of 'apparent' will be explained later. The upper three and the lowermost equations are obtained from displacement continuity, and the other three from the force balance.

The displacements of dashpots after a time increment, $\mathrm{dt}$ are calculated by the fourth-order Runge-Kutta method and the derivatives of $U_{d s i}$ are calculated as,

$$
U_{d s i}=k_{i} U_{s p i} / n_{i} \quad(i=1,2,3, \text { and } 6),
$$

where $n_{i}$ is the 'apparent' viscosity of the $i$-th dashpot. Then, $U_{s p i}$ at a time, $t+d t$ is calculated using these $U_{d s i}$ values in Eq. (1). This procedure is repeated for each time step.

When the force acting on the interplate earthquake fault becomes larger than the static friction, $F_{p 0}$, an interplate earthquake occurs and the friction suddenly decreases to a constant dynamic friction level, $F_{p 1}$. Deformations of the springs are calculated under the stress boundary condition resulting from $F_{p 1}$ as,

$$
\begin{gathered}
{\left[\begin{array}{cccccc}
1 & 0 & -1 & -1 & 0 & 0 \\
0 & 1 & 1 & 0 & -1 & 0 \\
0 & 0 & -k_{3} & k_{4} & -k_{5} & 0 \\
k_{1} & -k_{2} & k_{3} & 0 & 0 & -k_{6} \\
0 & k_{2} & 0 & 0 & k_{5} & 0 \\
1 & 0 & 0 & 0 & 0 & 1
\end{array}\right]\left[\begin{array}{c}
U_{s p 1} \\
U_{s p 2} \\
U_{s p 3} \\
U_{s p 4} \\
U_{s p 5} \\
U_{s p 6}
\end{array}\right]} \\
=\left[\begin{array}{c}
-U_{d s 1}+U_{d s 3}+U_{s l i} \\
-U_{d s 2}-U_{d s 3} \\
0 \\
0 \\
F_{p 1} \\
-U_{d s 1}-U_{d s 6}
\end{array}\right] .
\end{gathered}
$$

The fault displacement of the interplate earthquake (the change in $U_{s l p}$ ) is computed from the magnitude of the extension of the crust, namely the change in $U_{s p 4}+U_{s p 5}$. 


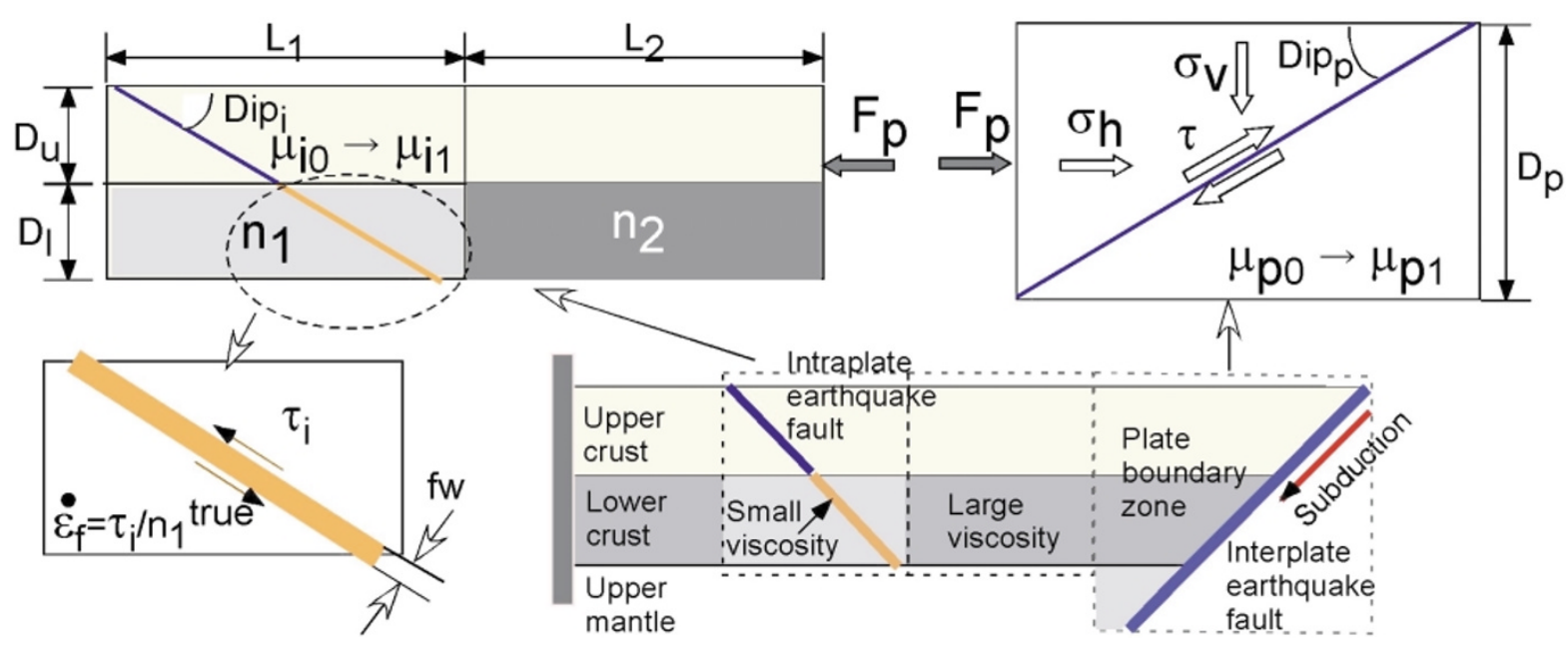

Fig. A.1. Geometries and material properties for the conceptual model. The plate boundary zone acts as a stress guide to transfer the force $\left(F_{p}\right)$ resulting from relative plate motions to the intraplate crust. $\dot{\epsilon}_{f}$ is the strain rate in the ductile fault zone and $\tau_{i}$ is the shear stress.

When the force acting on the intraplate earthquake fault becomes larger than the static frictional force, $F_{i 0}$, an intraplate earthquake occurs and the frictional force suddenly decreases to a constant dynamic frictional force level, $F_{i 1}$. The displacement of the spring connected to the slider $U_{s p 4}$ is computed as $U_{s p 4}=F_{i 1} / k_{4}$. Then, the displacements of the other springs and the slider $U_{s l i}$ are calculated from this value of $U_{s p 4}$ by the equations that are obtained by replacing $U_{s l i}$ with $U_{s p 4}$ in Eq. (1), under the fixed displacement boundary condition.

Next, we will attribute realistic values to the parameters and constants in the above equations. The frictions of the sliders, and the apparent spring constants and viscosities in the element model shown in Fig. 1(c) are related to material properties and geometrical constants of the conceptual intraplate crust and the plate boundary model, as described in Fig. A.1. The geometries of the intraplate and interplate earthquake faults are set with reference to typical examples in the Japanese Islands, as follows.

We first derive the relationship between the frictional forces $F_{p 0}$ and $F_{p 1}$ and the coefficients of friction $\mu_{p 0}$ and $\mu_{p 1}$ of the interplate earthquake fault. We assume only the horizontal force $F_{p}$ interacts between the plate boundary zone and the portions in the intraplate crust. Since we assumed that the reference stress state in the crust was lithostatic, we consider only a difference from this reference stress state as the horizontal stress, to calculate the deformation of the springs and dashpots. $F_{p}$ is calculated as, $F_{p}=\left(\bar{\sigma}_{h}-\bar{\sigma}_{v}\right) D_{p}$, where $\bar{\sigma}_{h}$ and $\bar{\sigma}_{v}$ is the depth-averaged horizontal and vertical stress, respectively, and $D_{p}$ is the coupling depth below which the friction of the interplate earthquake fault is assumed to be zero. Here, we assume the horizontal stress linearly increases with depth. Then, we only consider the stress at the center of the fault. The fault normal stress $\sigma_{n}$ is calculated as,

$$
\sigma_{n}=\frac{\bar{\sigma}_{h}+\bar{\sigma}_{v}}{2}+\frac{\left(\bar{\sigma}_{h}-\bar{\sigma}_{v}\right)}{2} \cos \left(2 D i p_{p}\right)
$$

where $\operatorname{pg} D_{p} / 2$, and $\operatorname{Dip}_{p}$ is the dip angle of the interplate earthquake fault. The shear stress $\tau$ is calculated as,

$$
\tau=\frac{\left(\bar{\sigma}_{h}-\bar{\sigma}_{v}\right)}{2} \sin \left(2 D i p_{p}\right) .
$$

At a time, $t, \bar{\sigma}_{h}-\bar{\sigma}_{v}$ is computed as

$$
\bar{\sigma}_{h}-\bar{\sigma}_{v}=F_{p} / D_{p}=\left(k_{2} U_{s p 2}+k_{5} U_{s p 5}\right) / D_{p},
$$

from the displacements in the crust. Then, from Eqs. (2) and (4), the static and dynamic frictional strengths at the center of the fault $\mu_{0}$ and $\mu_{1}$ are calculated as,

$$
\begin{aligned}
\tau_{0} & =\mu_{p 0}\left(\sigma_{n}-p\right) \quad \text { and } \\
\tau_{1} & =\mu_{p 1}\left(\sigma_{n}-p\right),
\end{aligned}
$$

respectively, where $p$ is the pore pressure and is assumed to be hydrostatic in the seismogenic fault. When $\mu$ becomes greater than $\mu_{0}$, an interplate earthquake occurs and $\mu$ suddenly decreases to $\mu_{1}$. The horizontal stress $\bar{\sigma}_{h}$ and force $F_{p 1}$ is computed by Eqs. (3), (4), and (6).

For the intraplate earthquake fault, $F_{i 0}$ and $F_{i 1}$ is computed in a similar way by using the coefficients of frictions $\mu_{i 0}$ and $\mu_{i 1}$ for the intraplate earthquake fault and the thickness of the upper crust, $D_{u}$, and the dip angle, Dip $p_{i}$. The relationship between the force acting in the portion of the crust that includes the earthquake fault, $F_{i}$, and the displacement of spring $U_{s p 4}$ is assumed as $F_{i}=E\left(U_{s p 4} / L_{1}\right) D_{u}$, where $E$ is the Young's modulus in the upper crust, and $L_{1}$ is the horizontal length of this portion. $U_{s p 4} / L_{1}$ is the strain in the portion in the upper crust that includes the earthquake fault. Thus, the apparent spring constant, $k_{4}$, which is defined as $F_{i} / U_{s p 4}$ is computed as $E / L_{1} D_{u}$.

For the ductile fault zone, the strain rate in the ductile fault zone, $\dot{\epsilon}_{f}$ is calculated as $\dot{\epsilon}_{f}=\tau_{i} / n_{1}^{\text {true }}=$ $E_{1}\left(U_{s p 1} / 2 L_{1}\right) \sin \left(2 D i p_{i}\right) / n_{1}^{\text {true }}$, wher $\tau_{i}$ and $n_{1}^{\text {true }}$ are the shear stress and true viscosity in the ductile fault zone, respectively. The horizontal velocity across the fault zone is calculated as

$$
\begin{aligned}
\dot{U}_{d s 1} & =\dot{\epsilon}_{f} f w \cos \left(\text { Dip }_{i}\right) \\
& =E_{l}\left(U_{s p 1} / 2 L_{1}\right) \sin \left(2 D i p_{i}\right) / n_{1}^{\text {true }} f w \cos \left(\text { Dip }_{i}\right)
\end{aligned}
$$


where $E_{l}$ is the Young's modulus in the lower crust, $f_{w}$ is the width of the ductile fault zone. Here, it is assumed that $f_{w}$ has a constant value. Then, the apparent spring constant, $k_{1}$ is computed as $E_{l} / L_{1} * D_{l}$ and the apparent viscosity, $F_{l} / \dot{U}_{d s 1}$ is $2 D_{l} / \sin \left(2 D i p_{i}\right) n_{1}^{\text {true }} / f w / \cos \left(\right.$ Dip $\left._{i}\right)$, where $F_{l}$ is the force acting on the lower crust that includes the ductile fault zone. For the ordinary lower crust, $\dot{U}_{d s 2}$ is calculated as, $\dot{U}_{d s 2}=\left(E_{l} U_{s p 2}\right) / n_{2}^{\text {true }}$, where $n_{2}^{\text {true }}$ is the bulk viscosity. The apparent spring constant, $k_{2}$ is $E_{l} / L_{2} * D_{l}$ and the apparent viscosity, $n_{2}$ is $D_{l} * n_{2}^{\text {true }} / L_{2} . n_{3}$ and $k_{3}$ are taken to be the same as $n_{2}$ and $k_{2}$.

\section{References}

Campbell, D. L., Investigation of the stress-concentration mechanism for intraplate earthquakes, Geophys. Res. Lett., 5, 477-479, 1978.

Hashimoto, C. and M. Matsu'ura, 3-D simulation of tectonic loading at convergent plate boundary zones: Internal stress field in and around Japan, paper presented at The 4th ACES workshop, Beijing, July 9-14, 2004.

Hinze, W. J., L. W. Braile, G. R. Keller, and E. G. Lidiak, Models for midcontinent tectonism: An update, Rev. Geophys., 26, 699-717, 1988.

Iio, Y. and Y. Kobayashi, A physical understanding of large intraplate earthquakes, Earth Planets Space, 54, 1001-1004, 2002.

Iio, Y. and Y. Kobayashi, Is the plastic flow uniformly distributed below the seismogenic region?, Tectonophysics, 364, 43-53, 2003.

Kanamori, H. and D. L. Anderson, Theoretical basis of some empirical relations in seismology, Bull. Seism. Soc. Am., 65, 1073-1095, 1975.

Kaufmann, G. and F. Amelung, Reservior-induced deformation and continental rheology in vicinity of Lake Mead, Nevada, J. Geophys. Res., 105, 16341-16358, 2000.
Kenner, S. and P. Segall, A mechanical model for intraplate earthquakes: Application to the New Madrid, Science, 289, 2329-2332, 2000.

Liu, L. and M. D. Zoback, Lithospheric strength and intraplate seismicity in the New Madrid seismic zone, Tectonics, 16, 585-595, 1997.

Matsu'ura, M. and T. Sato, A dislocation model for the earthquake cycle at convergent plate boundaries, Geophys. J., 96, 23-32, 1989.

Matsu'ura, M. and T. Sato, Loading mechanism and scaling relations of large interplate earthquakes, Tectonophysics, 277, 189-198, 1997.

Mcgarr, A. J. On the state of lithospheric stress in the absence of applied tectonic forces, Geophys. Res., 93, 13,609-13,617, 1988.

Nishimura, T. and W. Thatcher, Rheology of the lithosphere inferred from postseismic uplift following the 1959 Hebgen Lake earthquake, J. Geophys. Res., 108, 2389, doi:10.1029/2002JB002191, 2003.

Research Group for Active Faults of Japan, Active Faults in Japan, Sheet Maps and Inventories, Univ. of Tokyo Press, Tokyo, 1980.

Sibson, R., Continental fault structure and the shallow earthquake source, J. Geol. Soc. London, 140, 741-767, 1983.

Stuart, W. D., T. G. Hildenbrand, and R. W. Simpson, Stressing of the New Madrid seismic zone by a lower crust detachment fault, J. Geophys. Res., 102, 27,623-27,633, 1997.

Sykes, L. R., Intraplate seismicity, reactivation of preexisting zones of weakness, alkaline magmatism, and other tectonism postdating continental fragmentation, Rev. Geophys., 16, 621-688, 1978.

Ueda, H., M. Ohtake, and H. Sato, Postseismic crustal deformation following the 1993 Hokkaido Nansei-oki earthquake, northern Japan: Evidence for a low-viscosity zone in the uppermost mantle, J. Geophys. Res., 108, 2151, doi:10.1029/2002JB002067, 2003.

Zoback, M. L. and M. D. Zoback, State of stress in the conterminous United States, J. Geophys. Res., 85, 6113-6156, 1980.

Y. Iio (e-mail: iio@rcep.dpri.kyoto-u.ac.jp), T. Sagiya, and Y. Kobayashi 